\title{
COMPARATIVE MOTOR CYCLE PERFORMANCES
}

\author{
By D. S. HEATHER, B.So.
}

(Assootate Member).

IN a previous paper* the author dealt in some detail with the mechanical design of the motor cycle. In this paper he has confined his attention entirely to the performance of modern motor cycles and motor cycle engines, since, while there is now a considerable amount of published matter relating to mechanical questions, there is very little indeed relating to the performance of motor cycles.

He therefore trusts that this paper will not only prove of interest to those whose primary interests lie with the design and manufacture of four-wheeled vehicles, by reason of the opportunity which it gives for comparing the motor cycle with the car or the lorry, but that it will also be of use to those actually connected with the motor cycle industry, because it contains information which has not previously been collected into handy form.

The subject necessarily divides itself into three main sections:Tractive Resistance, Engine Performance and Road Performance. These three sections are dealt with in the paper in the order named.

Tractive Resistance.-It has been shown by Wimperis and others that the resistance to motion of a vehicle at varying speeds may be expressed with quite reasonable accuracy by the formula:-

$$
\operatorname{Tr}=\mathrm{A}+\mathrm{B} \boldsymbol{v}^{2}
$$

where $\operatorname{Tr}=$ resistance to motion (tractive resistance)

$$
v=\text { speed of vehicle. }
$$

$\mathrm{A}$ and $\mathrm{B}$ are constants depending on the particular vehicle and road.

This formula is not strictly true, sinoe it is likely that there are certain resistances which vary directly as the speed of the vehicle, so that $\mathrm{Tr}=\mathrm{A}+\mathrm{C} v+\mathrm{B} v^{2}$. Experimental data, however, show that the $\mathrm{C} v$ term has so small a constant as to be negligible. Unfortunately it is not possible to determine the constants analytically, by reason of their complex character. For instance, the

- See Proc. I. A. E., Vol. XIII., p. 247. 
constant A, which gives the term which is unaffected by the speed of the rehicle, is obviously related to the friction in the wheel bearings, and also to the rolling resistance of the tyres on the ground, which has been shown by Ewing and others to be substantially independent of speed in the case of pneumatic tyres. The bearing friction cannot be determined analytically with any accuracy, neither can the rolling resistance, particularly when it is remembered that it depends on the degree of inflation of the tyres, and also on the state of the road surface. The constant B is similarly complex, since although it is undoubtedly partly a questior of wind resistance, it may also contain some allowance for such losses as oil churning in the mechanism, the suction effect of tyres on a wet road, and losses due to the impact of the tyre on the road. An analytical determination being, therefore, impossible, the only possible method is to proceed experimentally.

In a paper read before the Institution in $1914,{ }^{*}$ Mr. Wimperis gave particulars of the method which he adopted. This consisted essentially in allowing the vehicle to decelerate with the clutch disengaged, measurements of the deceleration being made at intervals, by means of an accelerometer, as the car slowed down. These figures are then plotted on a velocity base, the resultant curve being, of course, a deceleration-velocity curve. The weight of the vehicle being known, and a suitable allowance being made for the inertia of the rotating parts, such as the road wheels, it is only necessary to alter the scale of ordinates to convert this deceleration-velocity curve into a resistance-velocity curve.

For example, suppose that the car to be tested weighed $1900 \mathrm{lb}$. complete, and that the equivalent weight of the rotating parts was $100 \mathrm{lb}$., so that the total weight for deceleration purposes could be taken as $2000 \mathrm{Ib}$., and that testing in the manner described above gave the following decelerations at the noted speeds, as plotted in Fig. 1:-

$$
\text { M.P.H. Deceleration. }
$$

ft. per seo. per see.

$10 \ldots \ldots \ldots \ldots \ldots \ldots \ldots \ldots \ldots, 0 . \ldots 2$

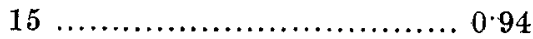

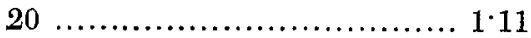

25 ............................ $1 \cdot 33$

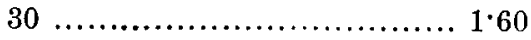

35 ............................ 1.91

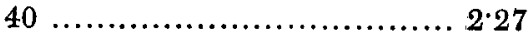

* See Proc. I. A. E., Vol. VIII., p. 281. 
Now it is evident that the deceleration at any particular speed bears the same ratio to the acceleration due to gravity that the decelerating force bears to the total weight of the car, so that, at 20 miles per hour, for instance, the tractive resistance

$$
\operatorname{Tr}=\frac{\text { deceleration }}{y} \times 2000=\frac{1.11 \times 2000}{32 \cdot 2}=69 \mathrm{lb} .
$$

In other words, it is only necessary to multiply the deceleration at any particular speed by $2000 / 32 \cdot 2=64 \cdot 1$ to obtain the tractive resistance at this speed, and to this the scale on the right of Fig. 1 corresponds. Examination of the curve shows it to follow the law $\operatorname{Tr}=45+0.06 v^{2}$, and it is, therefore, legitimate to say that the resistance to motion of the car is given by that equation. This, of course, applies only to the particular car under test, or to other cars of identical design, but it is evident that if tests are

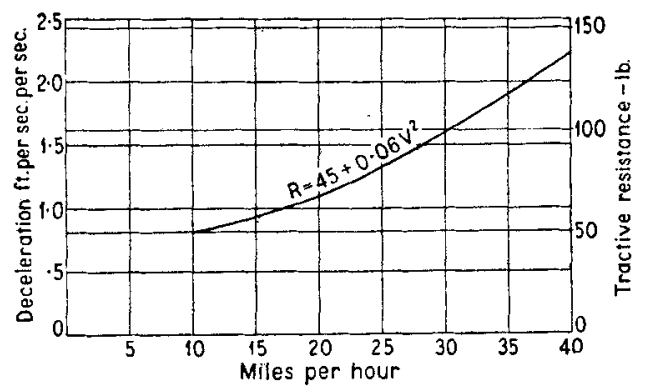

Fig. 1.-Deceleration Curve for Hypothetical Car.

Weight of car, $1900 \mathrm{lb}$.

Equivalent mass of rotating parts, $100 \mathrm{lb}$.

made on a sufficient number of dissimilar cars it will be possible to predict with reasonable accuracy the tractive resistance equation for almost any car.

The large number of tests which have been made on cars and lorries with the Wimperis and Lanchester accelerometers therefore cover the ground fairly well so far as four-wheeled vehicles are concerned, but unfortunately the author has failed to find any published results of tests on motor cycles or sidecar combinations, and he has, therefore, been constrained to obtain the necessary. experimental data himself. An accelerometer is of necessity a rather delicate instrument, and tests on two sidecar combinations with a Lanchester accelerometer of the autographic type showed that the vibration present on a motor cycle seriously interfered with the correct functioning of the instrument. 
The following alternative method of obtaining the desired information was therefore adopted. This method is simplicity itself, and requires no special instruments, since the whole of the figures required are obtained from an ordinary Bonniksen Isochronous Speedometer, manufactured by Messrs. Rotherham \& Sons, Ltd., of Coventry. This instrument works on the following principle:A gear wheel having fifty teeth is mounted on a shaft in such a manner that it can rotate with the shaft by friction through steel disks pressed up by a spiral spring, or it can be held in any definite position within the magnitude of one tooth, the shaft still revolving. The wheel is driven, through gearing, by the road wheel, and carries a small peg which comes against a stop when the pointer reaches zero. By this wheel, and by a duplicate of it, the recording hands are driven. The two hands record the speed alternately, the idle hand occupying the zero position. The pointer rests at zero until carried forward in the manner described below.

The speed record depends on two factors: (a) the rate of rotation of the fifty tooth gear, and (b) the length of time the gear wheel is allowed to rotate. The first faotor depends entirely on the speed of the road wheel, the second on the operation of a wateh escapement, itself actuated by the friction disks referred to above, and so arranged as to allow the pointer to rotate for exactly half a second, starting always from zero, and then to remain at rest for five seconds before returning to zero. Thus, if the road wheel is running at 50 miles per hour, the pointer goes once round the dial in half a second, but if the speed is only half this, the pointer only goes half round the dial in the half second available, and, therefore, stops at a reading of 25 miles per hour. When the hand has remained in position for five seconds the other hand comes up to position. Thus the instrument gives a speed reading every five seconds, this reading being the average speed of the vehicle over one half of a second, to the nearest mile per hour. For practical purposes it is sufficient to say that the instrumont gives the speed of the vehicle every five seconds. The indicating hand being definitely locked in position for five seconds, it is perfectly easy to read, there being no possibility of error through vibration or swinging of the indicating hand. When carrying out the tests, the machine is taken to a perfectly level stretch of road on a substantially windless day. It is then accelerated up to its maximum speed, and the gear lever slipped into neutral, the successive readings of the speedometer as the machine comes to a standstill 
being noted. To avoid the possibility of error, at least two runs in each direction are made, and averages taken for the final result.

The following figures were obtained in this manner on a 6/7 h.p. B.S.A. sidecar combination, fitted with a windscreen of the Easting type which was thrown right up into the storm protection

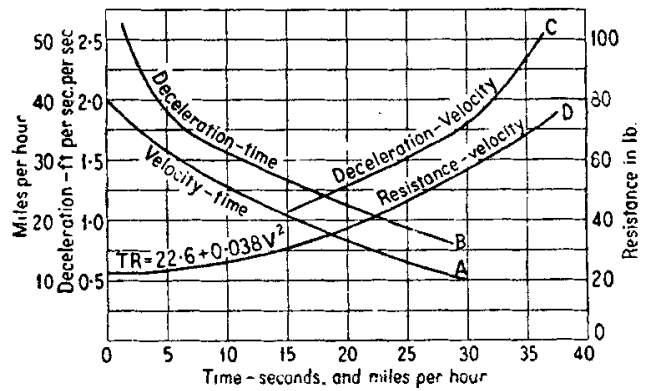

Fig. 2.-6 h.p. B.S.A. Combination.

Easting type screen-right up.

Total weight, $950 \mathrm{lb}$.

Road-perfect tarmac-dry.

position. The total weight of the outfit laaded, including an allowance for the inertia of the wheels, was $950 \mathrm{lb}$., and the tests were made on a stretch of perfect tar macadam. Successive readings of the speedometer as the machine slowed down were as follows:$40,31,25,21,17,13$ and 10 miles per hour. These are plotted

TABLE I.

\begin{tabular}{c|c|c|c}
\hline $\begin{array}{c}\text { Speed. } \\
\text { Miles per hour. }\end{array}$ & \multicolumn{2}{|c|}{ Resistance in lb. } & Error per cent. \\
& from Curve. & $\mathbf{R}=22 \cdot 6+0 \cdot 038 v^{2}$. & \\
\hline & $31 \cdot 0$ & $31 \cdot 0$ & 0 \\
20 & $37 \cdot 6$ & $37 \cdot 6$ & 0 \\
25 & 45 & $46 \cdot 1$ & $2 \cdot 4$ \\
30 & $53 \cdot 1$ & $56 \cdot 4$ & $6 \cdot 2$ \\
35 & $68 \cdot 6$ & $68 \cdot 7$ & $0 \cdot 15$ \\
\hline
\end{tabular}

in the lower left-hand curve $\mathrm{A}$ in Fig. 2 on a time base. Now it is evident that the slope of this velocity-time curve will give the deceleration-time curve, which is the upper left-hand line (B) in Fig. 2, and from the two curves it is a simple matter to draw the deceleration curve on a velocity base (upper right-hand line 
(C) in Fig. 2). This is the exact equivalent of the accelerometer curve given in Fig. 1. In the particular case under consideration, this curve, when measured off by the correct scale, gives the values for tractive resistance stated in the second column of Table I. Examination of these figures shows that the curve is substantially that represented by $\operatorname{Tr}=22 \cdot 6+0.038 v^{2}$, the figures given by this equation being given in the third column, while the fourth column gives the percentage error. These errors are of such a small order that it is evidently justifiable to say that the tractive resistance of this machine is adequately represented by the equation given above.

The author suggests that this method of obtaining the tractive resistance curve is probably quite as accurate as the accelerometer method, since it involves the reading of one instrument only, and that instrument gives absolutely dead beat readings. It is true that a little graphical work is required, but this is of a very simple nature, and the disadvantage is quite outweighed by the absence of the necessity of purchasing a special instrument for the work.

Since any determination of tractive resistance must of necessity involve a knowledge of the weight of the vehicle concerned, it will, perhaps, be as well to give a few particulars of the weights of modern motor cycles before proceeding further. For this purpose the author has analysed the figures given in the reports of the 1919 and 1920 A.C.U. Six Days' Trials, which figures include oil, petrol, and all kit. Little difference is to be observed between the figures for the two years, so that the weights actually given below are those for the 1920 Trial only. Arbitrary divisions have been made for the purpose of obtaining averages, these divisions corresponding roughly to distinct alterations in weight.

\begin{tabular}{|c|c|c|}
\hline Type of Machine. & $\begin{array}{c}\text { No. of Machines } \\
\text { averaged. }\end{array}$ & $\begin{array}{l}\text { Average Weight } \\
\text { in } 1 \mathrm{~b} \text {. }\end{array}$ \\
\hline 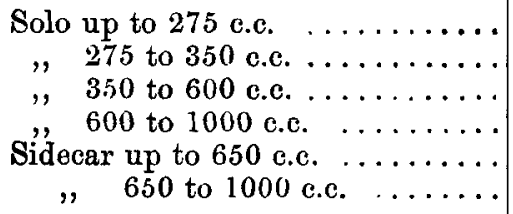 & $\begin{array}{r}14 \\
14 \\
49 \\
13 \\
7 \\
26\end{array}$ & $\begin{array}{l}198 \\
229 \\
297 \\
334 \\
460 \\
578\end{array}$ \\
\hline
\end{tabular}

It may be remarked that in the 350 ce. class the Blackburne engined machines were heavy, at about $252 \mathrm{lb}$. against an average 
of $229 \mathrm{lb}$., while the $3 \frac{1}{2}$ h.p. Precision machines in the same class weighed $287 \mathrm{lb}$, and have, therefore, been omitted from the average. The heaviest solo machine was the solitary 7-9 Indian, which weighed no less than $420 \mathrm{lb}$., or exactly the same as the A.B.C. sidecar outfits. The $4 \mathrm{~h}$.p. single-cylinder solo machines were very consistent, there being practically no variation between half a dozen makes. For instance, a $4 \frac{1}{4}$ h.p. B.S.A. machine weighed in at $280 \mathrm{lb}$., exactly the same figure as several $4 \mathrm{~h} . \mathrm{p}$. Triumphs, which is surprising in view of statements sometimes made that B.S.A. machines are heavy. Phelan \& Moore machines varied from 280 to $308 \mathrm{lb}$, while the $3 \frac{1}{2}$ h.p. Sunbeam machines were all round about $310 \mathrm{lb}$. Scott machines weighed $280 \mathrm{lb}$. like Triumphs, while the solo A.B.C. machines averaged $290 \mathrm{lb}$. Among the big sidecar machines Enfields were noticeable for their light weight, $532 \mathrm{lb}$., while the Matchless were heavy at an average of $651 \mathrm{lb}$. The effect of the spring frame is noticeable, for the $8 \mathrm{~h}$.p. Clyno was similarly heavy at $644 \mathrm{lb}$., while the A.J.S. outfits averaged about $580 \mathrm{lb}$.

Since certain machines were entered both solo and with a sidecar, it is possible to estimate the sidecar weights, which come out as follows:-

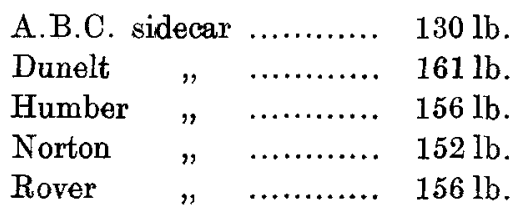

These figures may be compared with the following figures for standard 1921 B.S.A. machines, without accessories, fuel or oil.

$4 \frac{1}{4}$ h.p. B.S.A. Chain-Drive solo...... . . . . . . $262 \mathrm{lb.}$

$4 \frac{1}{4}$ h.p. "

$4 \frac{1}{4}$ h.p. $\quad$,

$4 \frac{1}{4}$ h.p. " ,

$4 \frac{1}{4}$ h.p. $\quad$,

$4 \frac{1}{4}$ h.p. "

$4 \frac{1}{4}$ h.p. $\quad$,

6 h.p. ,

6 h.p. ",

6 h.p. ,

6 h.p. ",

6 h.p. ,
Belt-Drive solo ....

Sidecar body and mudguard chassis, springs, wheel and tyre.. complete....

Chain-Drive combination complete ..... $418 \mathrm{lb}$.

Belt-Drive

Solo ....................... $350 \mathrm{lb}$.

Sidecar body

$97 \mathrm{lb}$.

, chassis, wheel, tyre and springs.. $113 \mathrm{lb}$.

", complete................ $210 \mathrm{lb}$.

Combination complete .......... $560 \mathrm{lb}$. 
No comment on these figures appears to be called for, but it is, perhaps, desirable to give some idea of the woight distribution on a typical sidecar combination, since the weight available on" the driving wheel is often the limiting factor in climbing freak hills. The following figures are for a $4_{4}^{1}$ B.S.A. combination with an 11 stone driver and a 13 stone passenger:-

\begin{tabular}{l|c|c|c|c|c|c|c}
\hline & Total. & \multicolumn{2}{|c|}{$\begin{array}{c}\text { Back Wheel. } \\
\text { Weight. per cent. }\end{array}$} & \multicolumn{2}{|c|}{$\begin{array}{c}\text { Front Wheel. } \\
\text { Weight. }\end{array}$} & \multicolumn{2}{c}{$\begin{array}{c}\text { Sidecar } \text { Whent. } \\
\text { Weight. per cent. }\end{array}$} \\
\hline Empty . . . & 504 lb. & $203 \mathrm{lb}$. & 40 & $182 \mathrm{lb}$. & 36 & $119 \mathrm{lb}$. & 24 \\
Driver only. $658,$, & $318,$, & 48 & $227,$, & 34 & $113, "$ & 18 \\
Full Load. & $840,$, & $350,$, & 42 & $276,$, & 33 & $214, "$ & 25 \\
\hline
\end{tabular}

It (will be observed that with the outfit fully loaded, 42 per cent of the total weight is on the rear wheel. Therefore, if the coefficient of friction between the tyre and the road is 0.5 , the tractive effort available is 21 per cent, or, in othertwords, the maximum grade which

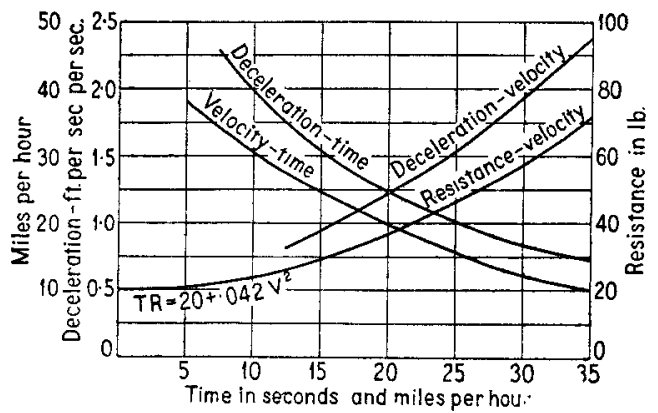

FIG. 3. -6 h.p. B.S.A. Combination.

No windscreen.

Gross weight, $950 \mathrm{lb}$.

Road surface-perfect.

$\operatorname{Tr}=20+0 \cdot 04 \underline{2} v^{2}$.

can be climbed is about 1 in 5 . The situation, however, is not so bad as this, because the effect of the gradient is to increase the rear wheel loading, and this tendency is still further helped by the driving torque, which is, of course, tending to lift the front wheel, 
and consequently to increase the load on the rear wheel. When it is remembered, however, that a really greasy surface probably gives a coefficient as low as 0.1 between the tyre and the road, it is easily seen that the proportion of total weight on the rear wheel is a most important matter. For ordinary use, nevertheless, a load distribution such as that given above is quite satisfactory

To return to the question of tractive resistance, Figs. 3,4 and 5 represent the results obtained from a series of tests on a $6 \mathrm{~h} . \mathrm{p}$. B.S.A. combination, which, with driver and passenger, and an allowance for the inertia of the rotating parts, had a gross weight of $950 \mathrm{lb}$. The tests were made on a perfect Tarmac surface under ideal conditions. The sidecar was fitted with a windscreen of the

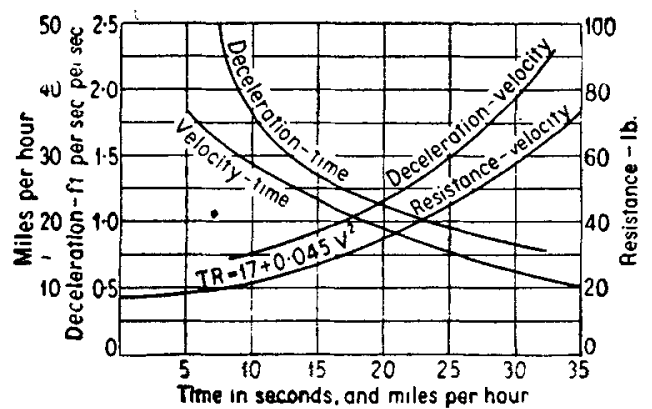

Fia. 4.-6 h.p. B.S.A. Combination.

Easting type screen in normal position.

Gross weight, $950 \mathrm{lb}$.

Road surface - perfect.

$\operatorname{Tr}=17+0.045 v^{2}$.

Easting type, and tests were made with the screen removed, with the screen in the normal position, and with the screen thrown right up, in order to determine what effect, if any, the screen had on the wind resistance. Figs. 3, 4 and 5 represent the conditions in the order istated, the resistance curves being-

$$
\begin{aligned}
& \operatorname{Tr}=20+0.042 v^{2} \\
& \operatorname{Tr}=17+0.045 v^{2} \\
& \operatorname{Tr}=22.6+0.038 v^{2} .
\end{aligned}
$$

These three resistance curves are plotted together in Fig. 6 for purpases of comparison. It is notable in the first place, that there is a considerable variation in the constant term. This is difficult to explain, but it has been noticeable in all the tests which have 
been made, and the author is inclined to think that it is due to the fact that the Bonniksen instrument reads only to the nearest mile per hour. The possible error thus introduced is unimportant at relatively high speeds, but may be of sufficient importance at low speeds to affect the constant factor. An independent check is easily made by finding the friction angle of the outfit, that is, the slope on which it will just keep rolling at a steady speed without either accelerating or decelerating. In this case it was found that $20 \mathrm{lb}$. was the correct figure. The equations may therefore be re-stated as-

$$
\begin{aligned}
& \text { No screen ........ Tr }=20+0.042 v^{2} \\
& \text { Screen normal .... Tr }=20+0.045 v^{2} \\
& \text { Screen up ....... Tr }=20+0.038 v^{2}
\end{aligned}
$$

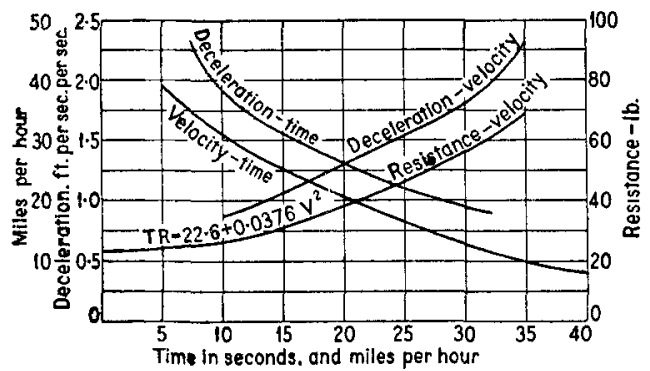

FIG. 5.-6 b.p. B.S.A. Combination.

Easting type screen right up.

Gross weight, $950 \mathrm{lb}$.

Road surface-perfect.

Tr. $=22 \cdot 6+0 \cdot 0376 v^{2}$.

The second point worthy of note is the very small effect of the screen on the $v^{2}$ term, which shows that a curved screen of the Easting type has very little effect at all on the wind resistance. Actually, the resistance is slightly less when the screen is thrown right up than when no screen is fitted, which is to be expected in view of its streamlining effect. With the screen in the ordinary position the resistance is slightly increased, but only to a negligible extent. These statements, of course, apply only when there is a passenger in the sidecar. When no passenger is carried the screen will slightly increase the resistance in all pasitions. It may further be noted that the constant term of $20 \mathrm{lb}$. is rather high. This is due partly to the fact that the machine was fitted with 28 in. $\times 3$ in. 
tyres run rather soft for the sake of comfort, and partly, perhaps, to the unusually large diameter of the bearings in the interchangeable wheels.

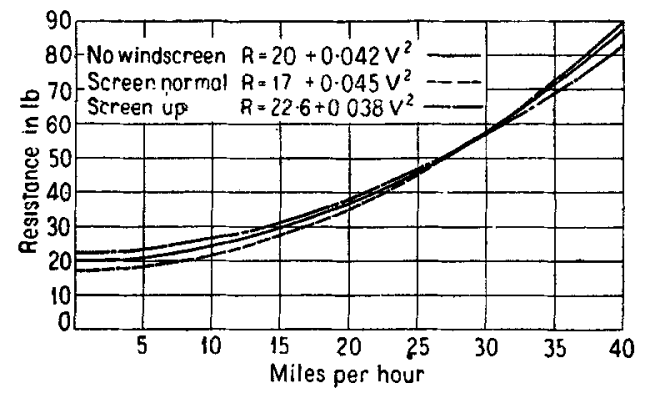

Fia. 6. -6 h.p. B.S.A. Combination.

Resistance velocity curves.

A similar series of tests was made on a 10 h.p. fourcylinder Henderson combination, fitted with a coach-built sidecar, the gross weight being $850 \mathrm{lb}$. In addition to the

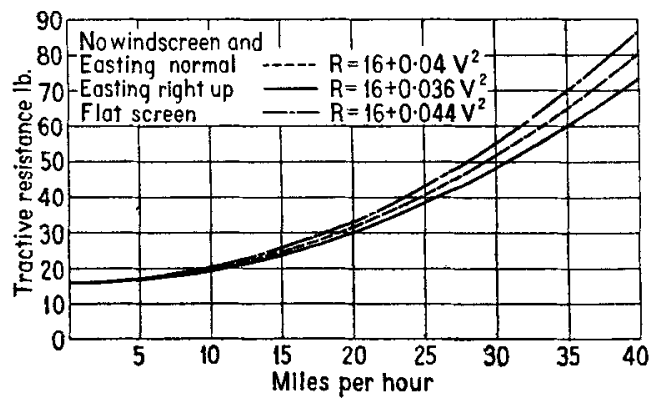

Fia. 7.-10 h.p. Henderson Combination (coach-built sidecar).

Tractive resistance curves.

Gross weight, $850 \mathrm{lb}$.

Road surface-perfect.

tests without a screen and with an Easting screen in the two positions, a test was made with a flat screen 18 in. high $\times 24$ in. wide, set at about 70 degrees to the horizontal. The resulting 
resistance curves are plotted in Fig. 7, and give the following results:-

$$
\begin{aligned}
& \text { No screen ........................ } \mathrm{R}=16+0.04 v^{2} \\
& \text { Easting screen, normal position ...... } \mathrm{R}=16+0.04 v^{2} \\
& \begin{aligned}
\text { Flat screen ............................ } \mathrm{R}=16+0.044 v^{2}
\end{aligned}
\end{aligned}
$$

It will be noted that in this case the addition of the Easting screen made no difference whatever to the resistance when set in the normal position, but that when right up it decreased the resistance as in the previous case. The use of a flat windscreen, however, increased the $v^{2}$ term by exactly 10 per cent, as would be expected. At 40 miles per hour the tractive resistance with

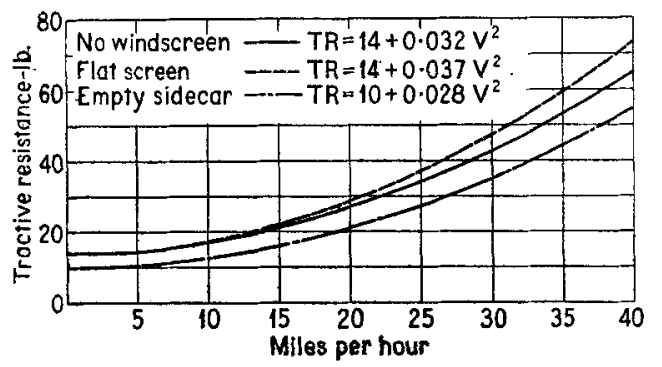

Fra. 8. -10 h.p. Henderson Combination (cane sidecar).

Tractive resistance curves.

Gross weight, $780 \mathrm{lb}$.

Road surface-perfect.

the flat screen is $12.7 \mathrm{lb}$. more than with the Easting screen in the best position, which represents a difference of no less than 1.35 h.p. in the power required to propel the machine.

The sidecar was then removed and replaced by a smaller cane sidecar, the gross weight of the outfit then being $780 \mathrm{lb}$. Tests were made with no screen, with a flat screen as before described, and also with the sidecar empty and covered by a tightly stretched apron so as to streamline it as far as possible. The resulting curves are shown in Fig. 8, and give results as follows:-

No screen $\operatorname{Tr}=14+0.032 v^{2}$

Flat screen $\operatorname{Tr}=14+0.037 v^{2}$

Sidecar empty ...... Tr $=10+0.028 v^{2}$

It may be noted here that the reduction in weight from $850 \mathrm{Ib}$. 
to $780 \mathrm{lb}$. gives a reduction of $2 \mathrm{lb}$. in the constant term, while the further reduction of $140 \mathrm{lb}$. in weight due to the absence of the passenger reduces the constant by a further $4 \mathrm{lb}$. This would appear to indicate that the constant might be taken at $2 \mathrm{lb}$. for every $70 \mathrm{lb}$. of weight. If this were the case, however, the constant term for the outfit at $850 \mathrm{lb}$. would be $24.3 \mathrm{lb}$. instead of the actual term of 16 . Before any definite decision as to the relation of this constant term to the total weight can be come to, therefore, it is evident that further experiments must be made with varying loads on the same machine. Unfortunately, the author has not, as yet, been able to find the necessary time to carry out these experiments.

As would be expected, there is a considerable reduction in the

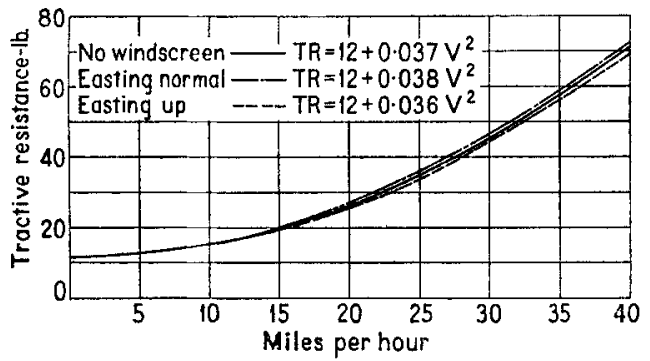

Fra. 9.-4 $\frac{1}{4}$ h.p. B.S.A. Combination.

Tractive resistance curves.

Gross weight, 780 lb.

Road surf 1 ce-perfect.

$v^{2}$ term when no passenger is carried, though the decrease is not so great as the increase caused by the use of a flat screen. Between the extreme conditions there is a difference in tractive resistance at 40 miles per hour of $18.3 \mathrm{lb}$, or no less than $1.96 \mathrm{~h}$.p.

A $4 \frac{1}{4}$ h.p. B.S.A. combination gives very similar figures, the rasistances under various conditions being as follows:-

No screen ............... Tr $=12+0.037 v^{2}$
Easting, normal …...... $\operatorname{Tr}=12+0.038 v^{2}$
Easting, up ............. $\operatorname{Tr}=12+0.036 v^{2}$

The weight of this outfit was $780 \mathrm{lb}$, and the wind resistance perhaps rather less than usual for that type of combination since the sidecar body was set very close in to the machine. The same machine was tested solo, with the rider sitting upright and then 
with head down in as near a racing posture as possible in view of the fact that the speedometer had to be kept in view. Resistances were as follows:-

$$
\begin{aligned}
& \text { Sitting up } \ldots \ldots \ldots \ldots . \operatorname{Tr}=8+0.02 v^{2} \\
& \text { Semi T.T. } \ldots \ldots \ldots \ldots . \operatorname{Tr}=8+0.015 v^{2}
\end{aligned}
$$

These figures are plotted in Figs. 9 and 10 respectively.

In Table II. the whole of the resistance figures which the author has obtained so far are tabulated, those marked with an asterisk having been deduced in each case from the performance of a machine of which the engine torque curve is known, while the remaindex have been obtained direct by the deceleration tests as described above.

Table III. gives a summary of the results in general terms, and covers all types and sizes of machines. In the case of sidecar

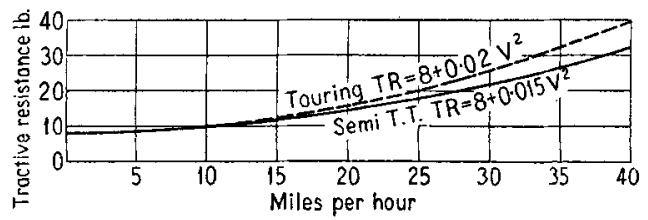

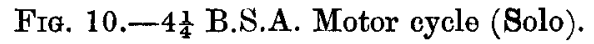

Tractive resistance curves.

Gross weight, $440 \mathrm{lb}$.

Road surface-perfect.

combinations, the projected area of the outfit, with driver and passenger seated, is given in order that the comparative sizes of the three classes for which figures are given may be realised. While, of course, these figures are not likely to represent very accurately the tractive resistance of any particular machine, yet the author feels sure that they are good average figures which may fairly be used for any analysis of the performance of a machine.

\section{Engine Performance.}

It is not an easy matter to obtain a representative set of power curves which will cover all sizes of engines. Some of the curves considered in the paper have been obtained by the author himself on a Froude Dynamometer, but for others he is indebted to various sources, including the technical press, and he is, therefore, unable to vouch for the accuracy of all the figures, though he has no reason 
TABLE II.

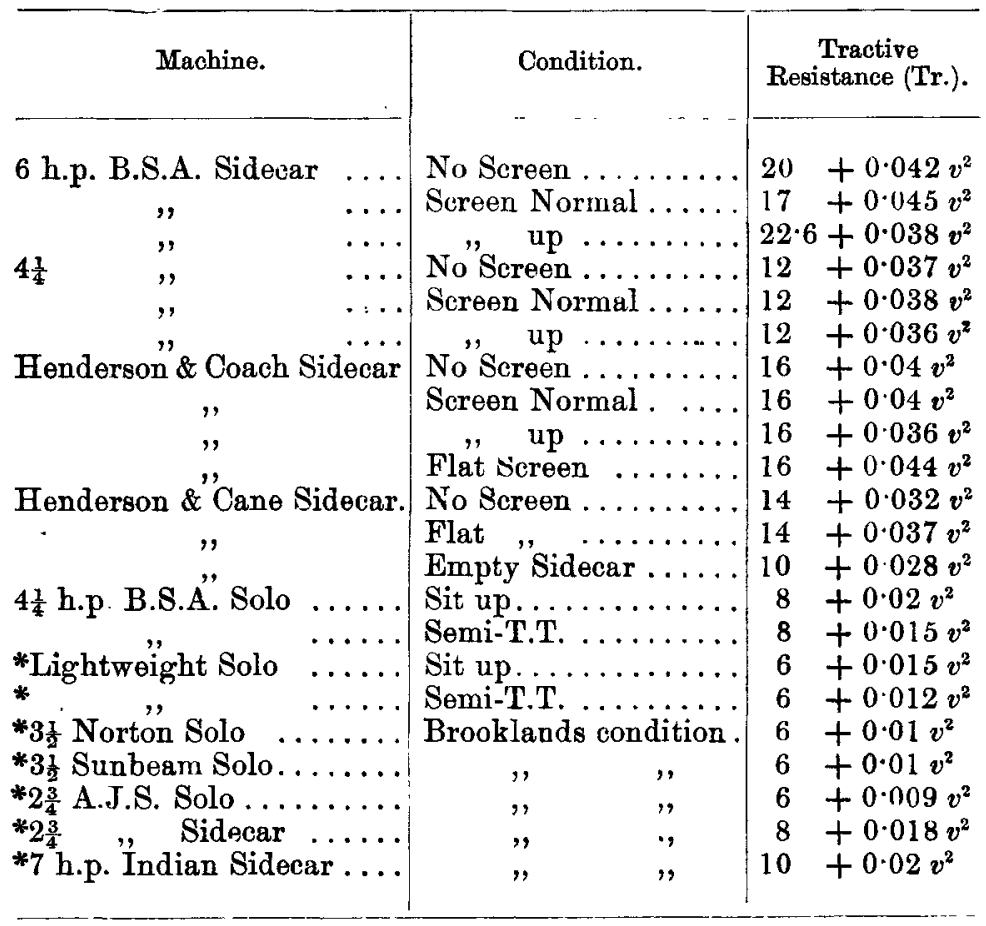

Table III.

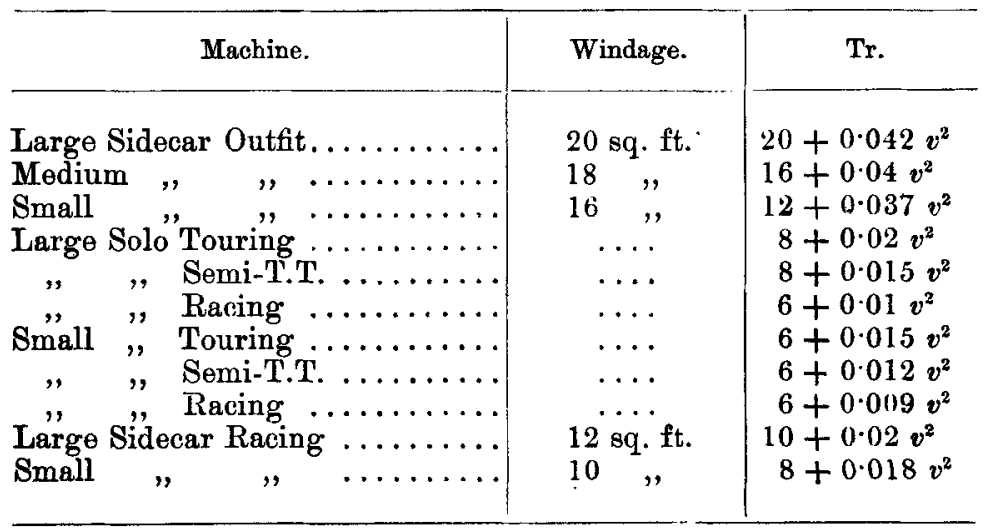


to think that any are far from the truth. In connection with this however, it must be remembered that air cooled engines are difficult to test on a dynamometer, because the power output varies somewhat with the eylinder temperature. A side-valve engine of normal design will often show a difference of 10 per cent in brake mean effective pressure between dead cold and steady hot running. By taking snap readings while the engine is cold, it is obviously possible to show a power curve which is considerably above what would be obtained were the readings taken with a hot engine. The author's method is to vary the velocity of the cooling air with the engine speed, and to wait until the engine has reached a steady temperature before taking any readings. Figures obtained in this

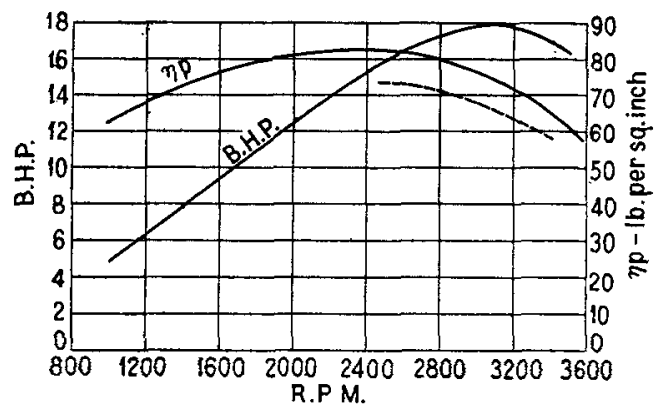

FrG. 11.-1918 Harley-Davidson 7-9 h.p. Engine.

Power ourves.

Capacity, 989 c.o.

Compression ratio, $3 \cdot 7$ to 1 .

way are evidently the only ones which are of any real value, and the point should always be borne in mind when power curves are analysed.

In Fig. 11 is given a power curve for a 1918 Harley-Davidson $7 / 9$ h.p. twin-cylinder engine. It will be noted that the peak of the horse-power curve gives $18 \mathrm{~h}$.p. at 3100 revs. per minute, while the maximum $\eta p$ is $83 \mathrm{lb}$. per sq. in. at 2400 revs. per minute. The dotted line is the $\eta p$ curve for a 1916 Henderson. This ourve has been deduced from the known tractive resistance and the known maximum speed of the machine on various gear ratios. The method is so obvious that it requires no explanation. It must be mentioned, however, that the Henderson being a hub-gearod machine, the tractive resistance figures refer to the back wheel, 
since the gear lever was slipped into neutral for the deceleration tests. The Harley-Davidson curve, however, is taken at the crankshaft. If an allowance of $\mathbf{9 0}$ per cent is made for the efficiency of the Henderson transmission, which includes bevel gear, crossshaft and chain, the Henderson curve approximates to that for the Harley-Davidson machine. Since the engines are of the same capacity, there is pvidently nothing to choose between them.

Fig. 12 shows the results obtained from a standard 6 h.p. B.S.A. engine, $76 \mathrm{~mm}$. bore $\times 85 \mathrm{~mm}$. stroke, giving a capacity of 770 c.c. The maximum horse-power produced was 13.5 at 3200 revs. per minute, while the peak of the $\eta p$ curve is $82 \mathrm{lb}$. per sq. in. at 2000 revs. per minute. Thus the maximum results

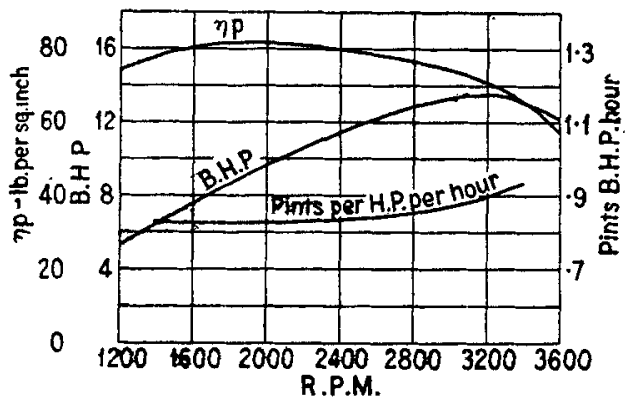

Fig. 12.-6 h.p. B.S.A. Engine.

Power curves.

Capacity, 770 c.c.

Compression ratio, $3 \cdot 6$.

obtained are substantially the same as in the case of the HarleyDavidson, but the B.S.A. engine is very much better than the other at lower speeds, and is, therefore, a better engine for touring purposes. The lowest curve is for petrol consumption with full throttle, in pints per brake horse-power per hour of No. 1 petrol using a B.S.A. carburettor.

The brake mean effective pressure curve shown in Fig. 13 is of an unusual shape and cannot be considered satisfactory. Since, however, it is drawn from the brake horse-power curve which was supplied by the makers of the well known $4 \mathrm{~h}$.p. flat twin engine concerned, it must be assumed to be correct. This engine, in any case, cannot be accused of suffering from what is generally considered to be the failing of many flat twins, namely, inability to 
pull at slow speeds. With the $\eta p$ curve still rising sharply at 1200 revs. per minute, it is evident that such an engine will be a slogger, but the speed droop will make it very bad for maximum power, which as a matter of fact only reaches $7 \cdot 2$ b.h.p. at 2600 revs. per minute.

The curves in Fig. 14 are for a 1920 type $4 \frac{1}{4}$ h.p. B.S.A. single-cylinder engine. Curve $A$, shown as a full line, is for a standard engine with the usual compression ratio of 3.52 to 1 . The test was made after the engine had been carefully tuned up to give the best results, the only alteration from standard being that a few holes had been drilled in the piston skirt. It will be noticed that the $\eta p$ is substantially constant at $83 \mathrm{lb}$. per sq. in.

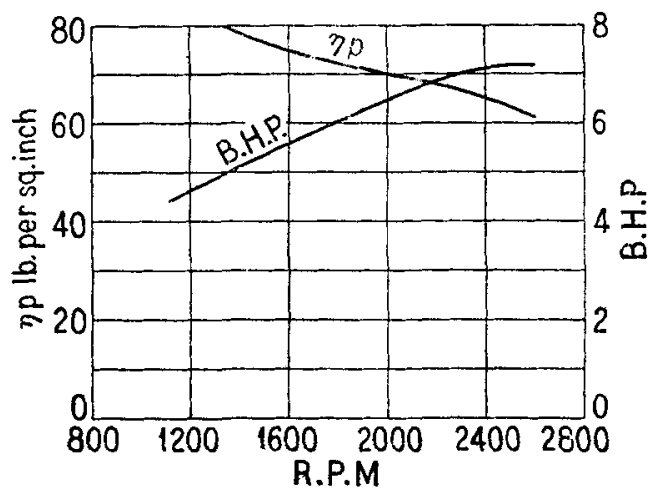

Fro. 13.-4 h.p. Flat Twin Engine.

Power Curves.

Capacity, 595 c.c.

from 1900 to 2500 revs. per minute. The maximum horse-power was 9.53 at 2900 revs. per minute. This engine was excellent on the raad, the sidecar machine in which it was fitted being considerably faster than most outfits of similar size. After several thousand miles running, the engine was again tested, without being tuned up, and curves B were obtained, giving a maximum $\eta p$ of $76 \mathrm{lb}$. per sq. in. and a maximum brake horse-power of 7.6 at 2700 revs. per minute. Only a few hours' skilled attention was necessary to bring the engine back to its original condition. Curves $\mathrm{C}$ are for a similar engine with a dome-topped piston, giving a compression ratio of 4 to 1 , and light reciprocating parts. Tuned up for sprint work, the engine gave an $\eta p$ of $93 \mathrm{lb}$. per 
sq. in. and $12 \cdot 25$ brake horse-power at 3300 revs. per minute. It would not, however, stand prolonged runs at full throttle and low revolutions, and for that reason was not so suitable for sidecar work as the engine with 3.5 to 1 ratio. It should be remembered that both these engines are of the standard side-valve type, with cast-iron pistons and ordinary cams. For instance, the valve timing of the engine to which curves $A$ and $B$ apply was as follows:-

Inlet opens 8 degrees late, closes 55 degrees late.

Exhaust opens 57 degrees early, closes 14 degrees late.

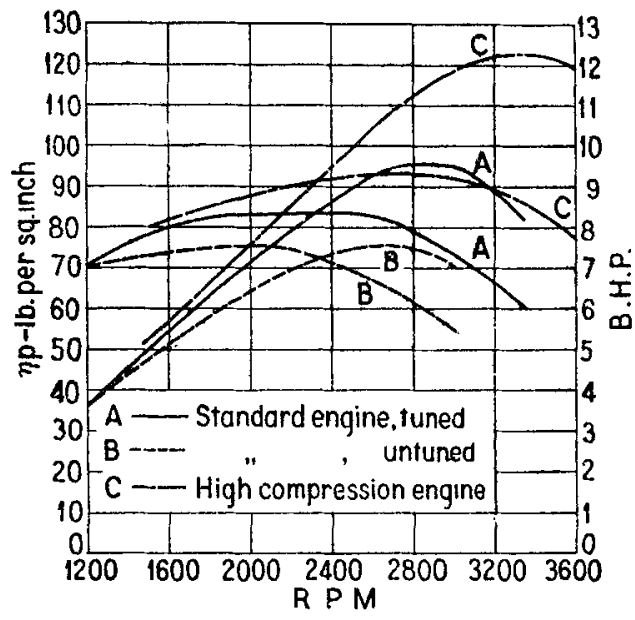

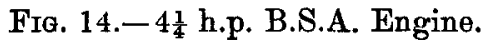

Power curves.

Capacity, 557 c.c.

Compression ratio, $3 \cdot 6$ to 1 .

It may be mentioned that a bench test of another make of $4 \mathrm{~h} . \mathrm{p}$. single-cylinder engine $85 \mathrm{~mm}$. bore $\times 97 \mathrm{~mm}$. stroke equal to 550 e.c. capacity, gave a maximum $\eta p$ of $76 \mathrm{lb}$. per sq. in. and a maximum brake horse-power of 9.2 at 2900 revs. per minute, which is not quite so good as eurve A in Fig. 14. With an open carburettor, the petrol consumption of the $4 \frac{1}{4}$ B.S.A. engine with the standard compression ratio is about 0.9 pints per brake horsepower per hour. With the standard air gauze fitted it falls to 0.8 pints, and if a special hot air pipe be fitted it may even be 
as low as 0.7 pints, all these figures, of course, being at full load with the carburettor jet wide open.

In Fig. 15 are curves for a 350 c.c. two-cycle engine of popular make. The horse-power curve $A$ was issued by the manufacturers in their advertising matter as an indication of the results obtained. It will be noticed that the maximum brake horse-power obtained is $4 \cdot 1$ at 2400 revs. per minute, while the corresponding $\eta p$ curve, also marked A, rises to a maximum of just over $34 \mathrm{lb}$. per sq. in. at 2100 revs. per minute. This, of course, corresponds to about $68 \mathrm{lb}$. per sq. in. in a four-cycle engine of the same nominal capacity, which is probably as high as would be obtained from the average touring engine of that size. An unsatisfactory. feature, however, is the extraordinarily rapid fall of the $\eta p$ curve

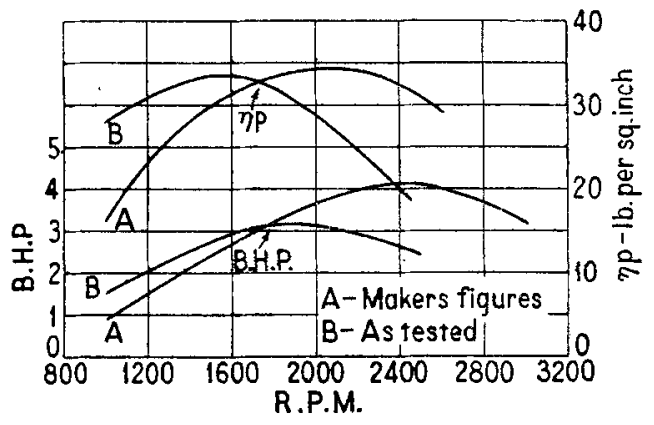

Fig. $15 .-350$ c.c. Two-cycle Engine.

Power curves.

on both sides of the maximum. The drop at higher revolutions merely means lack of maximum power, or inability to run fast, which is not a very serious fault for touring purposes. The rapid droop as the speed falls, however, is a most serious fault. The author was not surprised to find, therefore, that the engine was not really as bad as it was painted by its makers, for test of one which had done a thousand or so miles gave the results plotted in curves B in Fig. 15. It will be noted that these curves show a very much higher $\eta p$ at low speed; for instance at 1000 revs. per minute the figures are $16 \mathrm{lb}$. per sq. in. and $28 \mathrm{lb}$. per sq. in. On the other hand, the $\eta p$ falls, off alarmingly at speeds over 1600 revs. per minute, with the consequence that the maxinum brake horse-power reached was only 3.6 at 1900 revs. per minute. 
Nevertheless, there is no doubt that the $\mathrm{B}$ curves represent a much better touring engine than the $A$ curres issued by the manufacturers. As a matter of fact, the early speed droop on the B curves is probably due in part to the fact that the engine was tested in the condition in which it finished its road work, and the author has little doubt that reasonable attention would have improved the speed performances, though this might, perhaps, have been done at the expense of the lower end of the revolution scale. Unfortunately, no time was available for tuning up the engine to see what it would do at its best, so the curves in Fig. 15 must be left as they stand.

The author regrets that he has no power curve for a four-cycle engine of similar capacity, or for any two-cycle engines of the smaller elass, such as the 211 c.c. There is no reason, however, to suspect that they differ in their specific performance from the larger engines which have been considered, except that it is possible that a trifling loss in $\eta p$ may be obtained by reason of the greater loss of heat to the walls in the smaller cylinders.

A few interesting figures are obtainable as a result of analysis of various speed performances, an assumed value being taken for the tractive resistance, on the basis of the figures given in Table III. For example, the record-breaking 7-9 h.p. Indian which, ridden by Le Vack, recently did 95 miles per hour on a declared gear of $3.1 / 16$ to 1 , must have been producing an $\eta p$ of $91 \mathrm{lb}$. per sq. in. at 3500 revs. per minute, an exaellent figure for a side-valve engine, but not at all abnormal. The $3 \frac{1}{2}$ h.p. Norton, with O'Donovan up, did 83 miles per hour on a gear of $3.11 / 16$ to 1 , which means an $\eta p$ of $99 \mathrm{lb}$. per sq. in. at 4000 revs. per minute. A $2 \frac{3}{4}$ h.p. Douglas, with overhead valves and steel cylinders (pre-war type), was stated to give a maximum of 13 h.p. at 5000 revs. per minute, which means $96.5 \mathrm{lb}$. per sq. in. $\eta l^{\prime}$ at that speed. A $3 \frac{1}{2}$ h.p. Sunbeam giving $14 \frac{1}{2}$ b.h.p. maximum at 4250 revs. per minute shows $89 \mathrm{lb}$. per sq. in. These figures, of course, are not the maximums for $\eta p$, since the maximum horse-power is not reached until the mean effective pressure has fallen off considerably.

To take a different type of engine, a $3 \frac{3}{4}$ h.p. Scott was recently clocked at 69 miles per hour. Assuming the revolutions to be 2500 per minute, which is a reasonable figure for a two-oycle engine, the brake mean effective pressure would be $48 \mathrm{lb}$. per sq. in. on the gross volume, or $60 \mathrm{lb}$. per sq. in. on the nett volume, 
assuming the latter to be 80 per cent of the gross. On the other hand, the pre-war Singer machine, which for a considerable time held the hour record in the 350 c.c. class at 62.68 miles per hour, was geared $4.7 / 8$ to 1 , and was, therefore, doing substantially 4,000 revs. per minute for the whole hour. This gives an $\eta p$ of only $71 \mathrm{lb}$. per sq. in. Although this seems low after the figures given above, it must be remembered that the higher figures are definitely for sprint engines, which probably could not maintain their power for an hour at 4000 revs. per minute. In this connection it may be noted that at the time of writing this record is

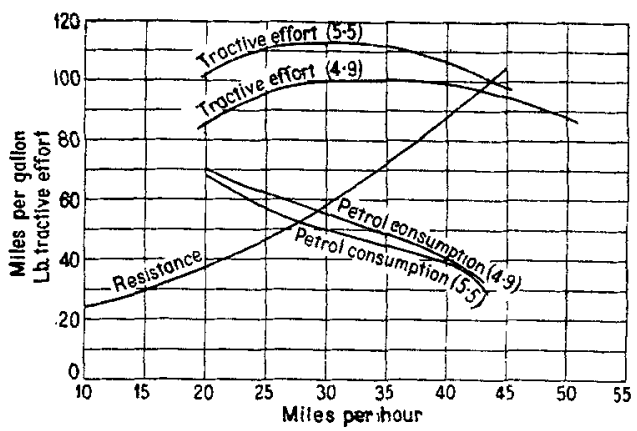

Fig. 16. -6 h.p. B.S.A. Combination.

Tractive effort and resistance curves.

No windscreen fitted.

Gross weight, $950 \mathrm{lb}$.

$\mathbf{R}=20+0.042 v^{2}$.

Gear ratio, 4.9 to 1 and $5 \cdot 5$ to 1 .

Maximum speed by curves $=42 \frac{3}{4}$ m.p.h. $(4 \cdot 9)$.

T.E." curve obtained from engine test 4-5-20, B.S.A. carburettor.

held by an overhead valve $2 \frac{3}{4}$ Douglas, at 63.69 miles per hour, only one mile per hour faster than the little single-cylinder Singer with its side-valve oylinder.

Lastly, the little $2 \frac{3}{4}$ h.p. A.J.S., which has made such sensational sprint performances, is said to give $13 \frac{1}{2}$ h.p. on the brake. Unfortunately, the author has no idea of the speed at which this is developed, so it can only be said that if the speed is 5000 revs. per minute, the $\eta p$ is $100 \mathrm{lb}$. per sq. in., if 4500 revs. per minute, $112 \mathrm{lb}$. per sq. in., or if 4000 revs. per minute, it is $125 \mathrm{lb}$. per sq. in. In any case the figures are remarkable enough. As to whether they can be maintained for any but short periods the 
author can only guess, but it is significant that up to the present only short distance records have been captured.

\section{Road Performance.}

In Fig. 16 the power curve given in Fig. 12 for a 6 h.p. B.S.A. engine has been converted into tractive effort curves, assuming the top gear ratios of 4.9 and 5.5 to 1 , which are the extremes of the range fitted by the B.S.A. Co. as standard. The tractive resistance curve is also shown, and it will be observed that this cuts the tractive effort curve for the 4.9 gear at $42 \frac{3}{4}$ miles per hour, and for the 5.5 gear at $43 \frac{3}{4}$ miles per hour, these speeds being, of course, the maximum passible on a good level road with no wind. These speeds, as a matter of fact, agree almost exactly with the author's observations on the road. Lest it be thought that this particular combination is unusually slow, it may be as well to point out that it can only attain a maximum possible speed of $\mathbf{4 4}$ miles per hour, for, at this speed, the resistance horse-power is exactly equal to the maximum horse-power produced by the engine. To give this, a gear of 6 to 1 is required if no wheel slip is allowed for, so that in all probability. $5^{\cdot 5}$ to 1 is about the fastest possible gear on the road.

The Harley-Davidson engine, the power curve for which is given in Fig. 11, with its maximum of substantially 18 h.p. at 3100 revs. per minute, would do just 51 miles per hour against the same resistance, and would need to be geared 5 to 1 . Since it is improbable that any ordinary touring engine produces more power than this example of the Harley-Davidson, it may fairly be said that 50 miles per hour is about the upper limit of speed for a fully equipped touring combination with large sidecar and screen. Reduction of the $v^{2}$ term in the resistance formula will, of course, increase the maximum possible speed very considerably, so that a racing outfit with this Harley-Davidson engine would probably do about 67 miles per hour. The 50 miles record is at present held by a Harley-Davidson sidecar with a speed of 68.97 miles per hour.

To return to Fig. 16, the lower curves represent the probable petrol consumption of the B.S.A. 6 h.p. combination at various. road speeds, as calculated from the bench tests and the tractive resistance curves. It will be noticed that the higher gear gives an advantage of about five miles per gallon over most of the range, although at the upper and lower limits the difference is not 
so great. These consumption curves, which agree very well with road results, show the immense importance of keeping the speed low if petrol economy is an object, since while the consumption may be 68 miles per gallon at a steady 20 miles per hour, it increases to 50 miles per gallon with an increase of speed to 30 miles per hour, and to 39 miles per gallon if the speed be increased to 40 miles per hour.

The liveliness and climbing power of the machine is obviously represented by the space between the tractive effort and tractive resistance curves, and Fig. 17 shows this on a horizontal base. The ordinates to the curve in Fig. 17 represent the excess tractive effort available at the speeds concerned, and, therefore, represent,

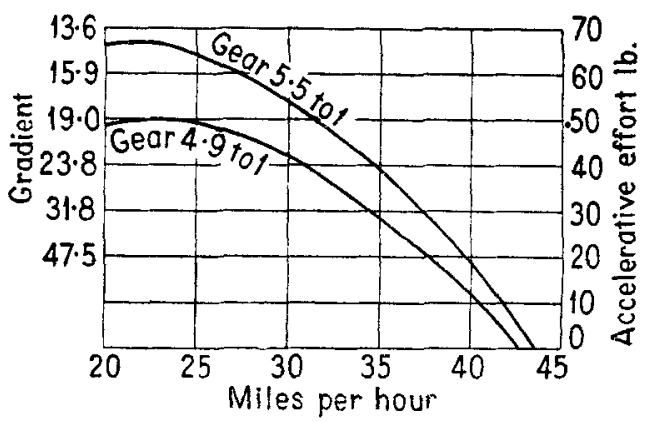

Frg. 17. -6 h.p. B.S.A. Combination. Acceleration and climbing capacity.

Gross weight, $950 \mathrm{lb}$.

Curves obtained from T.E. curves dated 27-6-20.

the accelerative effort or climbing capacity of the vehicle at each speed. The considerable advantage gained by the use of the lower of the two gear-ratios is at once evident, since over the whole range. there is very much better accelerative power available, together with an actual increase in the maximum speed. On the 4.9 gear, a steady gradient of 1 in 19 can just bo climbed, while on the 5.5 gear the maximum is 1 in 14.2 - a very great improvement, which more than outweighs the slight increase in petrol consumption.

The tractive effort curves on all three gears of the same combination are given in Fig. 18, together with the resistance curves on various gradients. The maximum gradient climbable on top gear is, of course, 1 in $14^{\circ} 2$ as shown in Fig. 17, while on the second gear 
1 in 8 is just possible, and on the first gear something steeper than 1 in 4 is covered. These figures refer to steady gradients which persist for a sufficient distance to destroy any momentum the machine may possess when it strikes the gradient. Very much steeper gradients may be climbed if the length of the steep pitch is short. It will be notioed that if maximum climbing speed is desired, it pays to change down from the top to the second gear at 30 miles per hour, and from the second to the first gear at about 20 miles per hour. In actual fact the machine will easily do 22 miles per hour on the first gear and 33 miles per hour on the second.

The performance of the $4 \frac{1}{4}$ h.p. B.S.A. combination on all gears

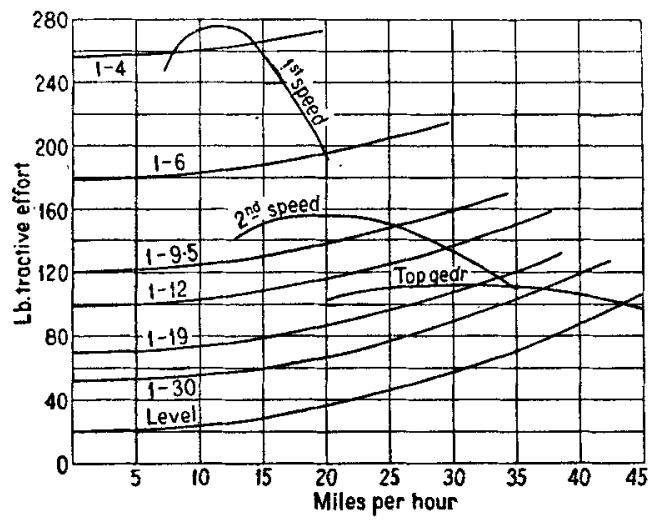

Fia. 18. -6 h.p. Combination.

Tractive effort and resistance curves.

Gear ratios, $5 \cdot 5,8 \cdot 5$, and 15 to 1 .

Gross weight, $950 \mathrm{lb}$.

$\mathbf{R}=20+0.042 v^{2}$.

is described graphically in Fig. 19. The curves are plotted to show what the author calls the accelerative ratio on the three gears of $5.5,8.8$ and 14 to 1 respectively at all road speeds. The accelerative ratio is merely the accelerative force of Fig. 17 divided by the gross weight of the machine. For example, in the case of the $4 \frac{1}{4}$ h.p. combination, reference to Fig. 9 will show that at 30 miles per hour the tractive resistance is $45.3 \mathrm{lb}$. The engine speed corresponding is 2150 revs. per minute, at which speed the engine is developing $83 \mathrm{lb}$. per sq. in. $\eta p$, which means a tractive effort of $95 \mathrm{lb}$. at the near wheel. Obviously, therefore, there is a surplus tractive effort of $49.7 \mathrm{lb}$. available for acceleration. 
or climbing, or for overcoming unfavourable road conditions. The ratio of this surplus tractive effort or accelerative force to the gross weight of the vehicle is 0.064 , and it is this which the author calls the accelerative ratio. Evidently an accelerative ratio of 0.1 is equivalent to the ability to climb a gradient of 1 in 10 , or to accelerate on the level at $3.22 \mathrm{ft}$. per sec. per sec.

Since the maximum accelerative ratio on top gear in Fig. 19 is approximately 0.08 , the maximum gradient climbable is 1 in $12 \frac{1}{2}$, while as the curve cuts the zero line at 43 miles per hour this is obviously the maximum speed. The second gear capacity is just short of 1 in 6 , while on the first gear 1 in $3 \cdot 2$ is possible.

It wili be seen, therefore, that on paper the performance of this

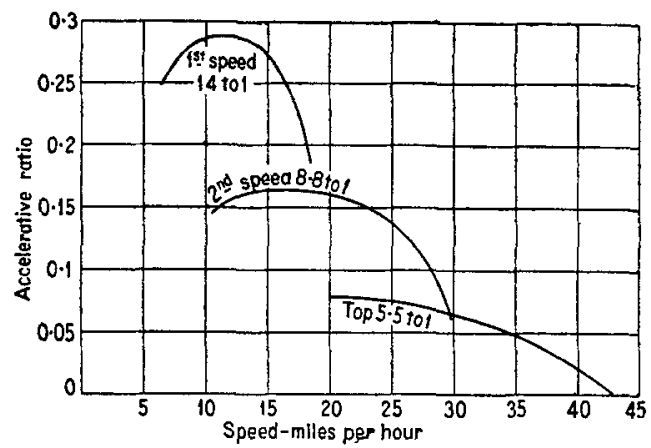

Fia. 19.-4 $\frac{1}{4}$ h.p. B.S.A. Combination.

Acceleration curves.

Gross weight, $780 \mathrm{lb}$.

outfit is substantially the same as that of the 6 h.p. combination. This is due largely to the fact that the $6 \mathrm{~h}$.p. outfit taken is unnecessarily heavily loaded, since its gross weight is $170 \mathrm{lb}$. greater than that of the $4 \frac{1}{4}$ h.p., as against an actual difference in the unladen weights of about $100 \mathrm{lb}$. The larger machine, moreover, is capable of considerably more rapid acceleration on the road than the single-cylinder engine in spite of equality on paper, due largely to the more even turning moment of the twocylinder engine.

The same machine solo is described by Fig. 20, in which the full line curves represent the performance of the machine on gearratios of $4 \cdot 75,7 \cdot 6$ and 12.2 to 1 respectively, the gross weight being taken to be $440 \mathrm{lb}$., and the rider presumed to be sitting 
bolt upright in the conventional but decidedly uncomfortable touring position. The power curve used is the full line in Fig. 14, which represents the results obtained from the standard engine. The maximum speed under these conditions is 53 miles per hour, with a top gear capacity of 1 in 7.5 at just under 30 miles pex hour. Second and first speeds will suffice for gradients of 1 in 3.8 and 1 in $2 \cdot 2$ respectively, so that it is evident that such a machine can never be stopped by gradient alone on any road in these islands provided a speed of about 10 miles per hour can be maintained. If the surface is so bad that 10 miles per hour is almost impossible, then the gear must be lowered, not to give a greater tractive effort but to make it effective at a lower road speed.

Returning to the top gear curves, the dotted curve represents

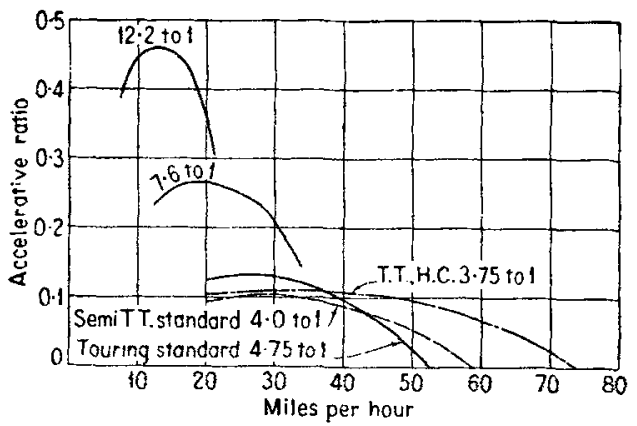

Fig. 20.-4 $\frac{4}{4}$ h.p. B.S.A. Solo.

Acceleration curves.

Gross weight, $440 \mathrm{lb}$.

exactly tho same machine with the gear raised to 4 to 1 , and the rider adopting a semi-T.T. position. This has the effect of pushing the maximum speed up to 59 miles per hour, and at the same time reducing the climbing capacity to 1 in 10 on the top gear. The chain curve is for the top gear performance of the high-compression engine of which the power curve is given in Fig. 14, with the rider in a full racing position and a gear ratio of $3 \frac{3}{4}$ to 1 . Note that the climbing and accelerative power remains excellent at all ordinary speeds, while the maximum speed possible has gone up to 74 miles per hour, assuming track resistances.

Similar curves may obviously be drawn for any other machines, provided that a power curve of the engine is available, but the author does not propose to pursue the subject farther, but to make a few remarks on the relative performances of cars and cycles. 


\section{CAR v. MOTOR CrCle.}

Taking first the engine, the motor cycle engine is, as a rule, of a somewhat lower compression ratio than the average car engine, and its ideal $\eta p$ is, therefore, correspondingly lower, while its ideal consumption is a trifle higher. In making comparisons, therefore. it is necessary to allow for this difference in compression ratio, and for this purpose the author has prepared the curves in Fig. 21, which show the variation of ideal $\eta p$ and consumption with varying ratios of compression. These curves are based on Ricardo's proposed standard of Attainable Ideal Efficiencies,* and while their exact accuracy may be of a doubtful order, their shape is certainly sufficiently nearly correct for purposes of comparison. From page 121 in the same volume the author has extracted particulars of a number of car engines, as given in Table IV., which shows the ratio of compression, the actual $\eta p$ developed, the ideal $\eta p$ from Fig. 21, and the percentage figure which is given by the ratio of actual to ideal. At the bottom are given figures for certain of the motor cycle engines already mentioned:-

TabLe IV.

\begin{tabular}{|c|c|c|c|c|}
\hline Engine. & R. & $\begin{array}{c}\text { Actual } \eta p . \\
\text { lb. per sq. in. }\end{array}$ & $\begin{array}{c}\text { Ideal } n p \text {. } \\
\text { lb. por sq. in. }\end{array}$ & Percentage. \\
\hline 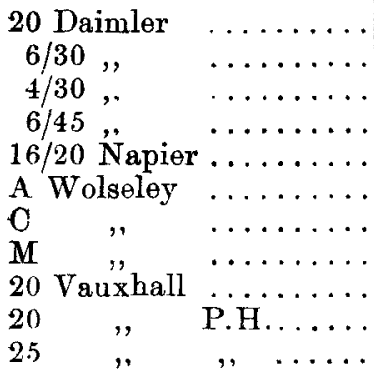 & $\begin{array}{l}4 \cdot 6 \\
4 \cdot 6 \\
4 \cdot 5 \\
4 \cdot 5 \\
4 \cdot 5 \\
4 \cdot 1 \\
4 \cdot 1 \\
4 \cdot 1 \\
4 \cdot 5 \\
5 \cdot 0 \\
4 \cdot 5\end{array}$ & $\begin{array}{r}88 \cdot 7 \\
90 \cdot 7 \\
87 \cdot 8 \\
87 \cdot 5 \\
83 \cdot 0 \\
77 \cdot 0 \\
81 \cdot 0 \\
79 \cdot 0 \\
85 \cdot 0 \\
104 \cdot 0 \\
90 \cdot 0\end{array}$ & $\begin{array}{l}118 \\
118 \\
117 \\
117 \\
117 \\
112 \\
112 \\
112 \\
117 \\
121 \\
117\end{array}$ & $\begin{array}{l}75 \\
77 \\
75 \\
74 \cdot 8 \\
71 \\
68 \cdot 8 \\
72 \cdot 3 \\
70 \cdot 5 \\
72 \cdot 6 \\
86 \\
77\end{array}$ \\
\hline $\begin{array}{l}4 \frac{1}{4} \text { B.S.A. Standard ... } \\
4 \frac{1}{4} \text {, H. H. . . . . . } \\
6 \text { h. . B.S.A. Standard. } \\
8 \text { h.p. Harley-Davidson.. }\end{array}$ & $\begin{array}{l}3 \cdot 52 \\
4 \cdot 0 \\
3 \cdot 6 \\
3 \cdot 7\end{array}$ & $\begin{array}{l}83 \cdot 0 \\
93 \cdot 0 \\
82 \cdot 0 \\
83 \cdot 0\end{array}$ & $\begin{array}{l}103 \\
110 \\
105 \\
106\end{array}$ & $\begin{array}{l}80 \cdot 5 \\
84 \cdot 5 \\
78 \cdot 0 \\
78 \cdot 0\end{array}$ \\
\hline
\end{tabular}

* See Proc. I.A.E., Vol. XIII, p. 120. 
It will be seen from these figures that motor cyclists have no need to be ashamed of the performance of their engines. The motor cycle engines quoted are by no means of special design; on the contrary, three of the four are ordinary standard engines as sold to the public for touring purposes, yet their performance is better than that of any car engine in the list except the $20 \mathrm{~h} . \mathrm{p}$. Prince Henry Vauxhall, which was a special high-efficiency engine designed solely for use in a sporting car.

A comparison of petrol consumptions is more difficult, since the author has not the data respecting the performance of car engines to enable a real comparison to be made. One example may, however, be taken. In Mr. Pomeroy's last paper, ${ }^{*}$ a large number of

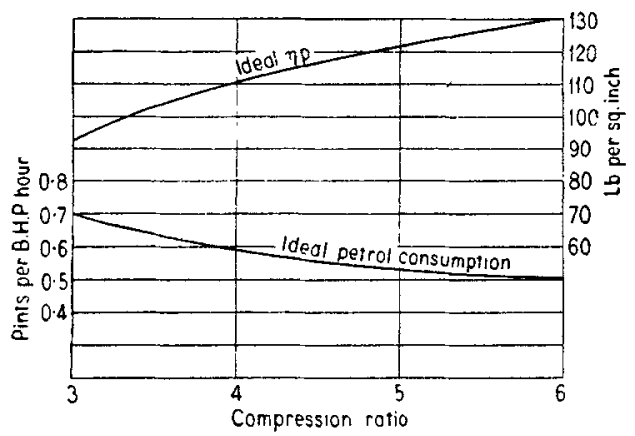

Fig. 21.-Ricardo's Ideal Engine Performance.

See Proc. I. A. E., Vol. XIII., p. 120.

petrol consumption figures were given, the best result obtained on the standard side-valve engine being 0.71 pints per brake horse-power per hour. This engine has a compression ratio of 4.8 to 1 , its ideal consumption from Fig. 21 being 0.54 pints. The actual is, therefore, $1 \cdot 32$ times the ideal. The 6 h.p. B.S.A., on the other hand, has a compression ratio of 3.6 to 1 , and its ideal consumption is, therefore, 0.63 pints against an actual consumption of 0.78 pints per brake horse-power per hour at the most economical point. The actual in this case is, therefore, 1.24 times the ideal. The $4 \frac{1}{4}$ h.p. B.S.A. gives 0.8 pints against an ideal of 0.635 , or a ratio of $1 \cdot 26$, while with a hot-air pipe fitted the consumption

* See Proc. I.A.E., Vol. XIII,, p. 163. 
actually falls to 0.7 pints per brake horse-power per hour, which is only $1 \cdot 1$ times the ideal.

From these few figures it does not appear that the petrol consumption of the motor cycle engine is other than good. It is certainly better than that of the car engine referred to above, when the variations in compression ratio are taken into account. Yet statements are frequently made to the contrary, and complaints have often been voiced in the technical press. Almost all of this dissatisfaction has been caused by the pernicious habit into which many people have fallen of talking of ton-miles per gallon. To use ton-miles per gallon as a standard of reference is always bad, and in the case of comparisons between such dissimilar vehicles as a motor cycle and a large car it is ridiculous.

Take for an example, a comparison between a 6 h.p. B.S.A. combination and a 20 h.p. Vauxhall car fitted with the engine referred to above. Mr. Pomeroy gives the weight of this car as 32 cwt., or 1.6 tons, and states that its petrol consumption is $24^{\cdot} 7$ miles per gallon at 20 miles per hour, and 23 miles per gallon at 30 miles per hour, so that this ear gives 39.5 and 36.8 ton-miles per gallon at 20 and 30 miles per hour respectively. Reference to Fig. 16 will show that the B.S.A. outfit, weighing $950 \mathrm{lb}$. gross, gives 68 and 50 miles per gallon at 20 and 30 miles per hour, or 28.9 and 21.25 ton-miles per gallon respectively. These are definitely worse figures than those given by the Vauxhall car so far as the ton-miles per gallon basis is concerned. If the figures are converted into pints per brake horse-power per hour, the results are very different. Assume that the Vauxhall resistance is represented by $40+0.07 v^{2}$, which is reasonable, especially as it gives a maximum speed agreeing with Mr. Pomeroy's statements. Then the tractive resistances at the two speeds are $68 \mathrm{lb}$. and $103 \mathrm{lb}$, and the tractive horse-power is 3.64 at 20 miles per hour and 8.23 at 30 miles per hour. The consumption is, therefore, 1.78 pints per brake horse-power per hour at the lower speed, and 1.27 pints per brake horse-power per hour at the higher speed.

The sidecar outfit requires $36.8 \mathrm{lb}$. tractive effort to drive it at 20 miles per hour and $57.8 \mathrm{lb}$. at 30 miles per hour, the respective horse-powers being 1.96 and $4 \cdot 62$. The consumptions are, therefore, 1.2 and 1.03 pints per brake horse-power per hour, at the chosen speeds, which compare very favourably indeed with the 1.78 and $1.2 \%$ pints obtained on the car. While, therefore, a comparison on the basis of ton-miles per gallon shows that at 20 miles per 
hour the car is apparently getting 1.37 times as much work out of a gallon of petrol as the sidecar, it is actually getting less than 70 per cent of the work when a correct analysis is made.

The reason for the failure of the ton-miles per gallon system as a basis of comparison is surely obvious. It is quite useless to compare the performance of different types of vehicles on a stan. dard which acknowledges weight only, when the deciding factor in the resistance to motion is not the weight at all but the winid resistance. Until, therefore, a formula is devised which will incorporate the $v^{2}$ resistance term as a basis of comparison, the only reasonable method of making a comparison between dissimilar vehicles is that which the author has used above.

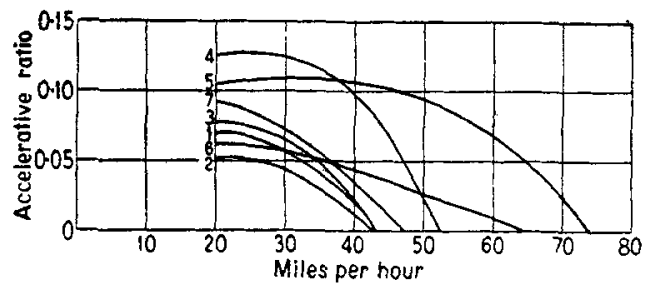

FIG. 22.-Accelerative ratio curves.

1. 6 h.p. B.S.A. Sidecar, $5 \frac{1}{2}$ to 1 top gear.

2. 6 , , , 4.4 to 1 ,"

3. $4 \frac{1}{4}, "$ ",$\quad 0 \frac{1}{2}$ to 1 ,"

4. $4 \frac{1}{4}, "$, , Solo, $4 \frac{3}{4}$ to 1 ",

5. $4 \frac{1}{4}$, , ," racing.

6. Vauxhall car.

7. $3 \frac{3}{4}$ h.p. Two-cycle solo, $3 \frac{3}{4}$ to 1 .

Note. - -3 also substantially represents 6 h.p. B.S.A. with normal weight of $860 \mathrm{lb}$.

Similarly, it is useless to attempt to compare the "liveliness" of dissimilar vehicles by a comparison of the respective ratios of brake horse-power to weight, or by using such figures as the maximum tractive effort in $\mathrm{lb}$. per ton. It is still more useless to make comparisons on the basis of thousands of litres per ton-mile, or similar figures, since such comparisons do not even take into account variations in $\eta p$ in different engines, in addition to the fact that they do not include any allowance for the $x^{2}$ term in the tractive resistance formula. The only reasonable means of comparing the performance of different vehicles is to draw the accelerative ratio curve for each vehicle, which, of course, neces- 
sitates a knowledge of the engine performance as well as the tractive resistance curve in each case.

The curves in Fig. 22 show the "accelerative ratio" curves for a representative set of motor cycles, and also for the Vauxhall car which has been taken for comparison. It will be observed that five of the curves are of substantially the same form, but the curre No. 6 for the car, and No. 5 for the racing motor cycle, are entirely different in character. This, of course, is due to the fact previously mentioned, namely, that the weight of the car affects its figures at the lower speed, whereas its wind resistance is small comparatively, and, therefore, the tractive effort required at high speed is less in comparison than it is in the case of a motor cycle. The curve for the racing motor cycle is similar to that of the car because the wind resistance of the machine has been reduced to the lowest possible limits, and its behaviour is, therefore, more like that of a car than of an ordinary touring motor cycle.

The figures in Table $V$. represent the "thousands of litres per ton-mile" for each of the vehicles included in Fig. 22:-

TABLE V.

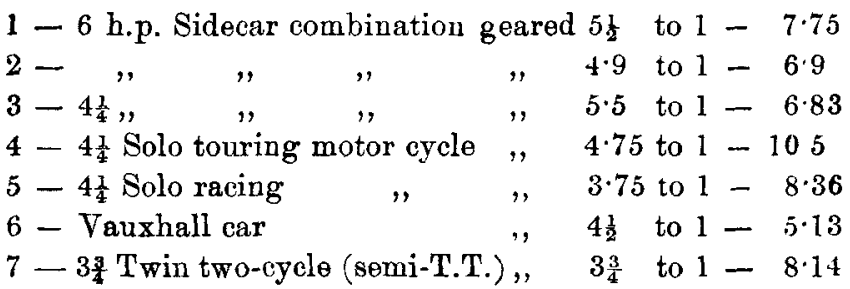

Comparison of these figures with the curves will show that the author's contention that any such basis of comparison is useless is fully justified. It will be seen that the car has the lowest figure of all, and yet is the second fastest vehicle, while the other figures bear very little relation to the real capabilities of the various machines on the road.

In conclusion, the author would like to point out that all the figures given for tractive resistance refer to good roads only, and that for bad road surfaces the constant factor must be largely increased. The author had originally hoped to give exact figures for the effect of road surface irregularities and for mud, and also to split up the $v^{2}$ tern into its components of wind resistance. and internal resistance. Unfortunately, however, the experiments 
are not in a sufficiently advanced stage to be worth recording, and it is only possible to say that it appears that the wind resistance accounts for about 70 per cent of the $v^{2}$ term.

The author feels, moreover, that it is necessary to apologise for the rather scrappy nature of the paper, but he trusts that the fact that it contains, to the best of his knowledge, a good deal of information as to the performance of the modern motor cycle which has not previously been published, will atone for the many omissions. 


\section{THE DISCUSSION.}

Mr. J. F. Henderson, in opening the discussion, said: It is certainly very satisfactory to see from Table IV. what high efficiencies have been got out of bicycle motors in comparison to the Air Standard Efficiency. Mr. Ricardo produced these curves to show how the efficiency of an engine could be improved by increasing the compression, and I think the author is making rather a virtue of a necessity in comparing the efficiencies on this basis, as of course the allowance for the comparatively low compression of the motor cycle engine makes it appear better than it would otherwise be. I agree with the author in his disapproval of a ton-mile basis as a standard for comparing the performance of vehicles unless they are fairly similar in type. After all, it is the distance which a gallon of petrol will carry a passenger which is the criterion of any passenger vehicle. I have, therefore, compared the various vehicles on this basis, with the following result:-

6 H.P. B.S.A. Combination at 30 M.P.H. ........ $15 \cdot 9$ H.P. Hispano-Suiza at 23-24 M.P.F. Ford ..............

6 H.P. B.S.A. Combination at 15 M.P.H. ........ 30 Seat Charabane $\ldots \ldots \ldots$. 6 H.P. B.S A. Combination at 18 M.P.H..........

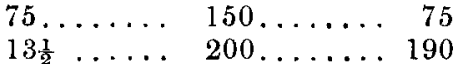

On page 846 the author says: "The driving torque which is, of course, tending to lift the front wheels and consequently to increase the load on the rear wheels"; with this I entirely disagree. I find that quite a number of engineers seem to think that this is the case, but it is an absolute fallacy, as I think I can show. A body will remain at rest or at uniform velocity in a straight line unless acted upon by some external force; conversely, if a body moves with uniform velocity in a straight line, the sum of all the external forces acting on it must be zero. If a vehicle, there- 
fore, is at rest on a perfectly smooth plane, either level or inclined, the only forces acting are the weight of the vehicle downwards through its centre of gravity, and the pressure of the road upwards at the points where the wheels touch the plane; the algebraic sum of these is zero. If we now consider the same vehicle travelling along the plane with a uniform velocity, the only additional forces excluding wind resistance, are a driving force acting on the rear wheel in the plane of the road and a resisting force at each wheel also in the plane of the road, and as these forces are in the samio line and their sum is zero, since the velocity is constant, there is no further couple acting on the vehicle, and therefore the loading on the front and the rear wheel will remain the same as it was when at rest. Looking at it in another way, if the vehicle is accelerated, it is clear that there will be a further couple tending to lift the front of the vehicle, and when it is decelerated the rear wheel of the vehicle will tend to rise. This is because the centre of the inertia of the whole mass is above the surface of the road. It is clear, therefore, that if we reduce both the acceleration and deceleration to zero, that is when the velocity is uniform, the couple tending to rotate the vehicle will vanish.

If we consider a vehicle on rails, say with the centre of gravity in the plane of the rails, there will be no couple produced, either when it is accelerated or retarded, as all the forces, including: those due to inertia, will be in the plane of the rails. Then, if we consider a vehicle, with the centre of gravity below the rails, the back wheel will tend to lift when it is accelerated, and the front wheel will tend to lift when it is retarded. If the road is not a plain surface and the gradient suddenly changes, the plane of the road which touches the front wheel will not be in line with the plane which touches the rear wheel, and there will then be a free couple tending to lift either the back wheel or the front wheel off the road, depending on whether the road gets steeper or less steep.

In an ordinary vehicle, the centre of wind pressure is at some height above the road, and therefore produces a couple, the effect of which is to reduce the load on the front wheel and to increase the load on the back wheel, increasing as the speed increasess.

It may be of interest to add that a vehicle running with uniform velocity along a road which is somewhat soft will usually be acted on by a couple slightly tending to throw more load on to the front wheel, which is exactly the opposite of what is usually 
(Mr. J. F. Henderson.)

supposed. As shown in Fig. 23, a 'small wave will form on the road surface in front of each wheel, so that each wheel will be continuously running slightly up-hill. The propelling force will, therefore, be in some such direction as $\mathrm{A} C$ coincident with the surface of the road at the point A. Part of this A B is balanced by the retarding force on the rear wheel A R1. The remainder of it, BC, is balanced by the retarding force F R2 on the front wheel.

These are, however, not now in line, and form a couple having an arm $\mathrm{R} 2 \mathrm{C}$. This couple tends to rotate the vehicle in an anti-clockwise direction, so throwing more load on to the front wheel.

Mr. J. Richardson: Anyone who has observed motor cycles travelling along our great highways must have come to the conclusion that their performances are really remarkable, and I

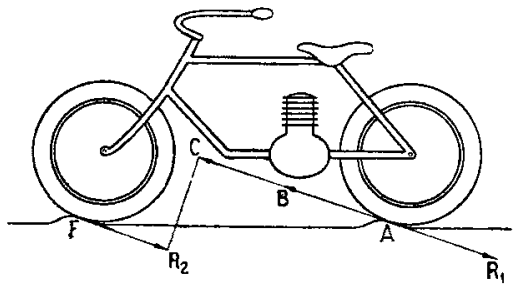

Fia. 23.

think that on the basis of the number of people carried, the motor cycle would compare very favourably with the charabanc, if it would not even surpass it. I am, therefore, not at all surprised on analysing the curves given in the paper (which are the first I have ever seen in connection with motor cycle and engine performance) to find that the efficiencies are of a remarkably high order.

I would have liked to have seen included some figures regarding piston speed, because surely the maximum revolutions possible with these engines is to some extent a function of the piston speed. I note the poor performance credited to the two-cycle engine. The brake mean effective pressure does not appear to rise in any case to above half of that achieved with the four-cycle engine. I would be glad if the author would enlarge upon this aspect of the subject and explain why two-cycle engines are fitted to motor 
cycles if their performances are so poor as is indicated in the curves given. Not only do they not seem to have the same. capacity for developing high speeds nor the same power at high speed, but lubricating oil and petrol consumptions are much higher than in the four-cycle engines. In spite of the instances of fine performances of the motor cycle, the author gave us clearly to understand that there is still open a large field for development. I do not understand why engines which give such high figures of output in sprint races cannot maintain these outputs, at all events approximately, over a much longer period than that of a sprint race. In other classes of engineering it is true that for purposes. of trial an extra degree of efficiency over and above the normal can be attained by the prime mover, but the difference between short trials and normal running is not usually nearly so marked as the author gives us to understand in regard to motor eycles. I would confidently expect that if and when the results of the intensive research and experimental work which was conducted during the war on air cooled aero engines were assimilated and applied to motor cycle engines, the large gap indicated could largely, if not entirely, be bridged.

Mr. J. A. McGillivray: Nearly all the records have been madie with long stroke engines, which appear to be directly against the case for low piston speed, although it is natural to assume that the limit of speed is reached at a certain piston speed. Regarding the charabane and motor cycle comparison, I saw an instance the other day of a sidecar machine with five up. If we take the. mileage per gallon at 75 , we arrive at the figure of 59 , which is as good as the charabanc. The author quoted a 4 h.p. machine represented to weigh about $200 \mathrm{lb}$. I saw one weighed recently minus lamp, horn and other unnecessary fittings and the weight came out at $197 \frac{1}{2} \mathrm{lb}$.

Mr. J. A. Martin: I quite agree with the author's conclusions with regard to the two-cycle engine. After running a lightweight two-cycle motor cycle for several years, I must say I. have never found it altogether satisfactory. It pulled well at low speeds and climbed hills very easily, giving an even torque up to about 18 miles per hour,' but above 25 the vibration became excessive and the power fell away considerably. This, I think, agrees with the torque and b.h.p.. curves given by the author. Then the petrol consumption was poor compared with that of a four-cycle engine of equal rated horse-power; 97 miles per 
(Mr. J. A. Martin.)

gallon was the best consumption I ever obtained. This was taken over a period of three weeks, during which the weather conditions were ideal, a definite known mileage being covered each day; under average running conditions, however, the consumption was between 60 and 70 miles per gallon. The engine was lubricated by the petroil mixture method, and though this is undoubtedly effective, the oil consumption was rather high for such a small engine. From the oily condition of the silencer and exhaust pipe it was evident that waste was caused by a portion of the oil going right through the engine.

Mr. J. WATt: The author has given us much useful information regarding acceleration and tractive effort, but he makes no mention of deceleration. I have yet to drive a sidecar combination incorporating a really efficient braking system. Apart altogether from the fact that the brakes themselves are very often not as powerful and reliable as they might be, only the rear wheel of the cycle is braked (the usual front brake may be ignored), and it would appear impossible to obtain sufficient adhesion from this one wheel. If the brake is really powerful, the rear wheel simply locks and skids. As an engineer, when driving a heavy sidecar combination, I would therefore feel much more confident if in addition to that on the rear wheel, a well-designed brake were applied to the sidecar wheel, although it must be admitted that this would be a very tricky brake to put into the hands of a novice. To put a direct question, could the author give any information regarding the maximum braking effort available with a $6 / 7$ h.p. B.S.A. combination?

Like Mr. Richardson, I have never had any great admiration for the two-cycle engine, particularly as applied to motor cycles. The four-cycle engine has reached such a high degree of mechanical perfection that engine trouble is to all intents and purposes unknown, and the slight mechanical complication is well worth the extra production cost chiefly because the petrol and oil consumption is so much better. An ordinary four-cycle sidecar outfit properly lubricated gives from 1,500 to 2,000 miles per gallon of engine lubricating oil, and my own $6 / 7$ h.p. B.S.A. sidecar machine shows a petrol consumption of 60.3 miles per gallon over 2,895 miles during a period of eight months, including losses due to short measure, evaporation and washing of parts. Comparing these figures with those quoted by Mr. Martin for a light two-cycle solo machine, it is evident that a big four-cycle engine pulling 
up to eight cwt. has given on the road practically the same petrol consumption as a two-cycle engined machine having a gross weight of 300 or $400 \mathrm{lb}$. In connection with petrol consumption in general, to obtain reliable figures the measurement must be based on a reasonably large mileage, say 3,000 or 4,000 miles, and a point that must be borne in mind is that the total volume of fuel used over even this distance is, after all, comparatively small, so that any leakage in the petrol system has a proportionately big effect on the number of miles per gallon. I really believe many motor cycle engines showing an apparently heavy consumption are being debited with petrol which never reaches the carburettor jet, simply because 10 per cent of the fuel or even more is being: lost at leaky cocks and unions. In comparing a motor cycle with a car, other factors besides petrol consumption must be considered. First cost, tyre wear, garage expenses, taxation and so on must be taken into account. It is very interesting for us as technical men to discuss miles per gallon and passenger-miles per gallon', but this does not go to the root of the matter, which from the user's point of view is, of course, running cost. No one can deny that a motor cycle and sidecar is the least expensive form of motoring: really it comes out cheaper than third class railway tickets.

I also would like to refer to the point brought up by Mr. Henderson. I must confess that until now my idea was that in ascending a hill the front wheel of a car or motor cycle tended to rise, due to torque reaction. If wind resistance is neglected, this would appear not to be the case so long as there is no change in velocity, and for those not mathematically-minded the matter can, perhaps, be explained in this way. Imagine two rails and on them a bogie with the top of the platform exactly on the plane of the rails: if a man were to lie on the platform and pull the bogie along by a rope, keeping the rope also on the plane of the rails, it is impossible to imagine any tendency for the front wheels to rise and still the bogie is being propelled. The next step is that, instead of hauling. the rope by hand, the man utilises a windlass, the centre line of: the rope being still in the plane of the rails. When he turns the handle of the windlass the bogie is again pulled along, and again it is not possible to imagine any tendency for the wheel to rise. The third step is to dispense with the rope. Imagine the windlass drum to be keyed to the axle of the wheels. The vehicle is then propelled by the adhesion of these wheels on the rails, and still there is no tendency to rise. The final step is that instead of 
(Mr. J. Watt.)

having a hand-operated windlass fixed to the wheels, this is connected up to an engine and the power derived from that. The position of the centre of gravity of the complete bogie, engine and windlass does not enter into the question so long as there is no change in velocity and, as we are neglecting wind resistance, neither are the projected area nor the centre of pressure factors to be taken into consideration.

Mr. J. D. PARKES: I have been struck by the extraordinarily good case made out by the author for the motor cycle as a vehic! and for its power unit as an internal combustion engine. Compared with the results obtained from bigger engines, some of the figures he gives are astonishingly good, though I feel I must disagree with his method of comparing the performance of motor cycle engines with that of car engines. It is all very well to assert that the motor cycle necessarily run's at a lower compression ratio, and then to make an allowance in respect of it. If it is necessary to run at such a low compression the fact is a disadvantage, and the motor cycle engine should be debited with it, instead of which the author credits it with an allowance which I think rather questionable.

As regards the question of the lifting of the front wheel of $a_{\text {, }}$ notor bicycle when moving at constant speed, I must admit that I held the popular opinion that the front wheel would lift, but after going into the matter fairly carefully I feol that this is incorrect, and, neglecting wind resistance, etc., the distribution of weight as between the two wheels remains constant, unless the machine is accelerating or decelerating.

As regards the point raised by several members in relation to the braking effort possible, it might be of interest to note that on a fully laden commercial vehicle of about 4 tons gross weight, on ideal road surfaces for adhesion, it is possible to obtain a decelerating force of up to $750 \mathrm{lb}$. per ton. This, however, is a maximum, because any further brake effort skids the wheel. Of course, on a motor cycle it might be impossible to reach such a figure as this because of loading difficulties.

Mr. Heather, in replying on the discussion, said: Mr. Henderson makes some interesting comparisons between motor cycles and other vehicles on the basis of passenger-miles per gallon. His figures, however, only prove my contention that any such basis of comparison is unfair when the comparisons are between 
vehicles of different types. He compares motor cycles with charabancs. I might as well compare charabancs with railway trains, when, on the passenger-mile basis, the charabanc would certainly be inferior. The only fair basis of comparison is that of direct analysis, which I have adopted in my paper.

Mr. Henderson disagrees with my statement that the front wheel tends to lift when hill-climbing. $\mathrm{He}$ has, I think, convinced my intelligence, but he has not convinced my imagination, for I have on many occasions seen the front wheel of a sidecan combination actually lift off the ground on a freak hill. What caused that? There must be some force acting which Mr. Henderson and Mr. Watt have failed to take into account, and there is evidently room for further analysis of the question.

So far as we have gone at present, the piston speed does not seen to be a limiting factor in engine speed at all as stated by $\mathrm{Mr}$. Richardson. The limiting factor is probably the pumping efficiency due to the fact that for dynamic reasons there is a limit to the port openings which can be obtained with poppet valves.

The two-cycle engine is used on motor cycles for two reasons. It is cheap to manufacture, and it provides a more even torque than a four-cycle engine with the same number of cylinders. The standard of performance on two-cycle engines as used for motor cycles is not high, and therefore any small firm can produce a two-cycle engine which will give average results. I believe, however, that there is a considerable field for the two-cycle engine if it is carefully studied, and that its petrol consumption can be made to compare favourably with that of the average four-cycle engine. A considerable amount of research is, however, required before this state of affairs can be reached.

The difference between the horse-power obtained for short sprints and that which can be maintained for long periods is largely due to heating of the new charge causing a reduction in the volumetric efficiency as the engine warms up. Since an air cooled engine reaches much higher temperatures than a water cooled engine, the effect is obviously more marked. Also pinking troubles have to be contended with, again due to temperature. I believe that during the next twelve months considerable advances may be expected in this direction, but it is hardly reasonable to expect that results as good as those quoted by Dr. Gibson. in his paper will be obtained, since these refer to slow running 
(Mr. Heather.)

aero engines cooled by a steady breeze. Our engines run threo times as fast, and under much worse cooling conditions.

Several speakers asked for figures of braking effort. Under good conditions the rear brake on a sidecar combination should give $500 \mathrm{lb}$. per ton, which is quite as good as the average car. The figure given by Mr. Parkes is for a commercial vehicle with a large portion of its weight on the rear wheels. Our sidecar taxis are fitted with brakes on the sidecar wheel, but I should not care to fit such a brake as standard, as it is a very trickyi thing to use. There is no reason, however, why a good front brake should not be fitted, which, in conjunction with the rear brake, would give about $800 \mathrm{lb}$. per ton, which is ample.

Mr. Parkes criticised the fact that in comparing car and cycle engines I allowed for the lower compression ratio used in the latter. I cannot see any alternative. I was dealing with engines as they exist to-day, and was therefore bound to take into account such a fundamental factor as the ratio of compression. Most of my figures are for ordinary touring engines as sold to the public. Had I dealt in detail with racing engines, using compression ratios even higher than those used by cars, the figures would probably have been rather astonishing, for the results obtained are certainly good. 